\title{
A STUDY ON PHYTOCHEMICALS, FUNCTIONAL GROUPS AND MINERAL COMPOSITION OF ALLIUM SATIVUM (GARLIC) CLOVES
}

\author{
B. J. DIVYA, B. SUMAN, M. VENKATASWAMY, K. THYAGARAJU\# \\ Department of Biochemistry, Sri Venkateswara University, Tirupathi 517502, Andhra Pradesh \\ Email: thyagarajuk_1999@yahoo.com
}

Received: 28 Dec 2016, Revised and Accepted: 20 Mar 2017

\section{ABSTRACT}

Objective: The present study on garlic cloves (Allium sativum) belongs to family Amaryllidaceae has been focused. This is a natural medicinal plant used for disease preventions against all kinds of internal infections. Preliminary screening of phytochemicals has found plenty of secondary metabolites which are present in garlic cloves. Their functional groups and mineral compositions, the potential of trace elements have been evaluated using FTIR and inductively coupled plasma optical emission spectrometry (ICPOES).

Methods: The screening of phytochemicals, FTIR and ICPOES. All the methods were performed by standard protocols.

Results: The phytochemical screening of plant extracts of hexane, ethyl acetate, methanol and water revealed the presence of steroids, saponin, alkaloids, flavonoids, glycosides, phenolic compounds, terpenoids and carbohydrates. The results of the methanolic extract of $A$. sativum analysis showed rich bioactive compounds. The FTIR spectroscopic studies revealed characteristic peak values from $3500-1000 \mathrm{~cm}-1$ for various functional compounds like hydroxyl, carbonyl, carboxylic and organosulfur and aromatic compounds in the garlic methanolic extract. The elements present in the garlic play an important role in the treatment of various diseases described in the traditional medicinal system. The elemental analysis was carried out on garlic methanolic extract using the ICP-OES technique and it showed the order of abundance as $\mathrm{K}>\mathrm{P}>\mathrm{Mg}>\mathrm{Ca}>\mathrm{Zn}>\mathrm{Al}$ that could enhance the curative process of ill health and the potentially toxic elements were not detected.

Conclusion: Thus our data on garlic shows a great importance to understand the pharmacological actions and therapeutic efficacy possessed by majority of active compounds.

Keywords: Alkaloid, Flavanoid, Glycoside, Phenolic compound, Terpenoid, FTIR, ICPOES, Allium sativum

(C) 2017 The Authors. Published by Innovare Academic Sciences Pvt Ltd. This is an open access article under the CC BY license (http://creativecommons.org/licenses/by/4.0/) DOI: http://dx.doi.org/10.22159/ijcpr.2017v9i3.18888

\section{INTRODUCTION}

Medicinal plants are the richest bio-resource of drugs of traditional systems of medicine, modern medicines, nutraceuticals, food supplements, folk medicines, pharmaceutical intermediates and chemical entities for synthetic drugs [1]. The plants are rich to contain several active principles with specific therapeutic effects. They represent a source of chemical compounds such as tannins, flavonoids, saponins resins, alkaloids etc with curative properties [2]. Plants offer a large range of natural compounds belonging to different molecular families which have various useful properties to humans. The medicinal plants are useful for healing of human diseases because of the presence of active constituents [3]. Phytochemicals are occurring in whole plants, leaves, vegetables, roots and seeds. The plant products induce defence mechanism and protect the organisms from various diseases. Medicinal plants play a major role in meeting the medical and health needs of about $70 \%$ of populations in developed and developing countries, which serve as an important resource for the treatment of various diseases [4].

The present medicinal plant selected for the study is Allium sativum, commonly known as garlic, belongs to the family Amaryllidaceae. Garlic is probably one of the earliest known medicinal plants [5]. Garlic and its preparations have been used extensively in health benefits, resulting in numerous research reports over the last decade alone. Garlic is widely consumed spices in food, while also consumed in the form of drink [6]. A. sativum bulbs (cloves) had been used as a cure-all. In ancient Egypt, they are mentioned in the Ebers Papyrus, as one of the earliest treatises on medicinal plants. Garlic contains sulfur-containing compounds [7]. The fresh bulb contains an alliin, allicin and volatile oils when the garlic clove is crushed, the odourless compound alliin is converted to allicin via the enzyme allinase. Allicin gives garlic its characteristic pungent smell [8]. It contains vitamins, minerals and trace elements [9]. On the other hand, garlic is a herbal medicine which is used for prevention and treatment of many diseases such as, cold and flu symptoms through immune enhancement and exhibits anticancer, antioxidant, anti-inflammatory, antimicrobial, antithrombotic, hypocholesterolemic, hypoglycemic, and hypotensive activities. And it is used to treat diabetes, atherosclerosis, hyperlipidemia, thrombosis and hypertension. Also, it acts against stroke, gastrointestinal neoplasias, against blood clots (antiplatelet action) etc.

The main aim of the present study was to screen the phytochemical constituents present in garlic cloves by different solvents like hexane, ethyl acetate, methanol and water and find the secondary metabolites with functional moieties which are present in cloves by FTIR and to identify the mineral composition by ICPOES. The attempt was made to study in detail for further research.

\section{MATERIALS AND METHODS}

\section{Collection of plants and preparation of extracts}

The Allium sativum bulb cloves were identified and authenticated by plant Taxonomist, Department of Botany, Sri Venkateswara University, Tirupati, Andhra Pradesh and voucher specimen no SVUBH/1123 was stored. The fresh bulb cloves were purchased from the Local market of Tirupati, Chittoor district of Andhra Pradesh and were shade dried and peeled off. They were milled to a fine powder using a mechanical grinder. The powder was macerated with hexane, Ethyl acetate, methanol and water, separately. The extract was then filtered with filter paper (Whatman No. 1) and the filtrate under reduced pressure, using rota evaporator at $40{ }^{\circ} \mathrm{C}$, was concentrated. The concentrate obtained was a dark molten mass then layered on aluminium foil and freeze-dried for further use.

\section{Phytochemical screening}

An alianof of the dry extracts of garlic were used for phytochemical examinations to detect the secondary metabolites such as Alkaloids, 
saponins, carbohydrates, flavonoids, cardiac glycosides etc. by using standard procedures/methods with slight modifications $[10,11]$.

\section{Inductively coupled plasma optical emission spectrometry (ICP- OES) digestion}

The contents of metals present in the garlic were determined using ICP-OES after the digestion of the samples with concentrated $\mathrm{HNO}_{3}$ and analyzed for $\mathrm{Zn}, \mathrm{Mg}, \mathrm{Ca}, \mathrm{P}, \mathrm{Al}$ and $\mathrm{K}$ in triplicate and the procedure as per method [12].

\section{Fourier transform infrared spectrophotometer (FTIR)}

The infrared spectroscopy was used to detect the functional groups of biomolecules present in the mixture of the sample. The garlic methanol extract was mixed with potassium bromide salt, using mortar and pestle, and compressed into a thin pellet and sample was put into IR spectrometer. The results were recorded on a FTIR spectrometer between the range $3500-1000 \mathrm{~cm}^{-1}$. The wavelength of light absorbed is characteristic of the chemical bonds as can be seen in the annotated spectrum.

\section{RESULTS AND DISCUSSION}

Fresh garlic is a rich source of vitamins, minerals and trace elements, although most are found in only minute quantities. Our study has revealed the presence of phytochemicals considered as active medicinal chemical constituents of garlic extracts indicated the presence of phenolics, alkaloids, flavonoids, steroids, glycosides, and saponins etc (table 1). Among all the solvents methanol extract showed more number of constituents when compared to hexaneethyl acetate and water. Tannins are present in water and in remaining all extracts it is absent.

The cardiac glycosides are present in hexane, ethyl acetate, methanol and water. Due to the secondary metabolites which are present in the garlic cloves, it is used in many parts of the world as a stimulant, carminative, antiseptic, antihelminthic (ascaris and oxyuris), diaphoretic, expectorant, diuretic, antiscorbutic aphrodisiac and antiasthmatic, in pulmonary diseases such as croup, whooping cough, tuberculosis, bronchoectasis and gangrene, many more ailments [13].

Table 1: Qualitative analysis of the phytochemicals of the garlic

\begin{tabular}{lllll}
\hline Secondary metabolites & Hexane extract & Ethyl acetate extract & Methanol extract & Aqueous (water) extract \\
\hline Alkaloids & - & + & + & + \\
Saponins & - & - & + & + \\
Steroids & - & - & + & + \\
Carbohydrates & - & + & - & + \\
Flavonoids & - & + & + & + \\
Tannins & + & + & + & - \\
Terpenoids & - & + & + & + \\
Anthraquinone & + & + & + \\
Phenolics & + & + & + \\
Cardiac glycosides & + & & + \\
\hline
\end{tabular}

+indicates presence,-indicates absence

The ICP-OES is one of the fastest analysis to simultaneously determine several minerals present in garlic extract. This technique is expensive but has good sensitivity and accuracy in determining minerals which we used in our study such as $\mathrm{Zn}, \mathrm{Mg}, \mathrm{Ca}, \mathrm{P}, \mathrm{Al}$ and $\mathrm{K}$ etc. The values of different metals present in the garlic cloves methanolic extract samples (ppm) are listed in table 2. The order of concentration of elements showed the following $\mathrm{K}>\mathrm{P}>\mathrm{Mg}>\mathrm{Ca}>\mathrm{Zn}>\mathrm{Al}$. potassium $(\mathrm{K})$ is one of the important elements for many regulatory systems in the body. The minimum daily intake of Potassium is $3.5 \mathrm{~g}$ [14]. This mineral has many functions for human health, like transmission of nerve impulses, muscle contraction, regulation of blood pressure, maintenance of acid-base equilibrium and waterelectrolyte balance. Furthermore, some studies have supported that $\mathrm{K}$ is involved in skeleton health and in the prevention of Na-induced calciuria promoting reabsorption of $\mathrm{Ca}$ in the kidney and reducing urinary Ca excretion [15-17]. Calcium (Ca) is an important element because it plays a major role in bones, teeth, muscular system and heart functions. Calcium is necessary for the coagulation of blood, the proper functioning of the heart and nervous system and the normal contraction of muscles [18]. Daily Ca intake lower than the recommended one could have serious negative effects for human health, like the onset of osteoporosis, very common in menopausal women, hypertension, colon and breast cancer [19-20].

Phosphorus is essential for bone, skin, hair and teeth health, energy metabolism, fatty acids transport, phospholipid synthesis, amino acids metabolism and protein synthesis. This mineral is also a component of nucleic acids and consequently, it is involved in cellular metabolism and in buffer and enzyme systems [16]. Intracellular Magnesium deficiency is correlated with the impaired function of many enzymes utilizing high energy phosphate bonds, as in the case of glucose metabolism [18]. The recommended dietary intake of $\mathrm{Mg}$ is about 310$320 \mathrm{mg}$ per day for females and 400-420 mg per day for males. Magnesium is important for human health because it regulates many physiological processes, such as bone growth, blood pressure, protein and nucleic acids metabolism, neuromuscular trasmission and muscle contraction. Besides, Mg acts as a cofactor of many enzymes and has an important role in reducing asthma. Magnesium deficiency can increase the risk of osteoporosis, mainly in menopausal women, the risk of atherosclerosis and lead to oxidative stress [17]. Zinc is essential to all organisms and has an important role in metabolism, growth, development and general well-being. It is an essential cofactor for a large number of enzymes in the body [18].

Table 2: Mineral compositions of garlic cloves methanol extract

\begin{tabular}{ll}
\hline Minerals & Values(PPM) \\
\hline Potassium & $21,278 \pm 395.39$ \\
Phosphorus & $6003 \pm 54.744$ \\
Magnesium & $1046.15 \pm 25.618$ \\
Calcium & $353.61 \pm 0.02$ \\
Zinc & $28.42 \pm 1.32$ \\
Aluminum & $23.15 \pm 0.801$ \\
\hline
\end{tabular}

From the FTIR of methanolic extract showed the presence of functional groups like hydroxyl, carbonyl, carboxylic and organosulfur compounds (from table 3 and fig. 1). The broad peak at $3265 \mathrm{~cm}^{-1}$ is due to the $\mathrm{O}-\mathrm{H}$ stretching of a hydroxyl group which 
indicates the presence of polyhydroxy compounds such as flavonoids, non-flavonoids and saponins. The peak at $2926 \mathrm{~cm}-1$ is due to the asymmetric stretching of $\mathrm{C}-\mathrm{H}$ groups of aromatic compounds. The peak at $1619 \mathrm{~cm}^{-1}$ is corresponding to $\mathrm{C}=0$ stretching of peptide linkages $/ \mathrm{C}=0$ stretching of carbonyl and carboxylic groups. The peak at $1395 \mathrm{~cm}^{-1}$ indicates the $0-\mathrm{H}$ bend of carboxylic acids [21] which in turn revealed the presence of flavonoids, tannins, saponins and glycosides. The peak at $1036 \mathrm{~cm}^{-1}$ indicates the $\mathrm{S}=0$ group revealed the presence of organosulfur compounds including alliin, allicin and diallyl disulphide [22].

Table 3: FTIR peak values and functional groups of garlic methanolic extract

\begin{tabular}{lll}
\hline Frequency $\mathbf{~ c m}^{-1}$ & Bonds & Functional groups \\
\hline 3265 & $\mathrm{O}-\mathrm{H}$ & Hydroxyl \\
2926 & $\mathrm{C}-\mathrm{H}$ & Aromatic compounds \\
1619 & $\mathrm{C}=\mathrm{O}$ & Carbonyl and carboxylic \\
1395 & $\mathrm{O}-\mathrm{H}$ & Carboxylic \\
1036 & $\mathrm{~S}=\mathrm{O}$ & Organosulfur \\
\hline
\end{tabular}

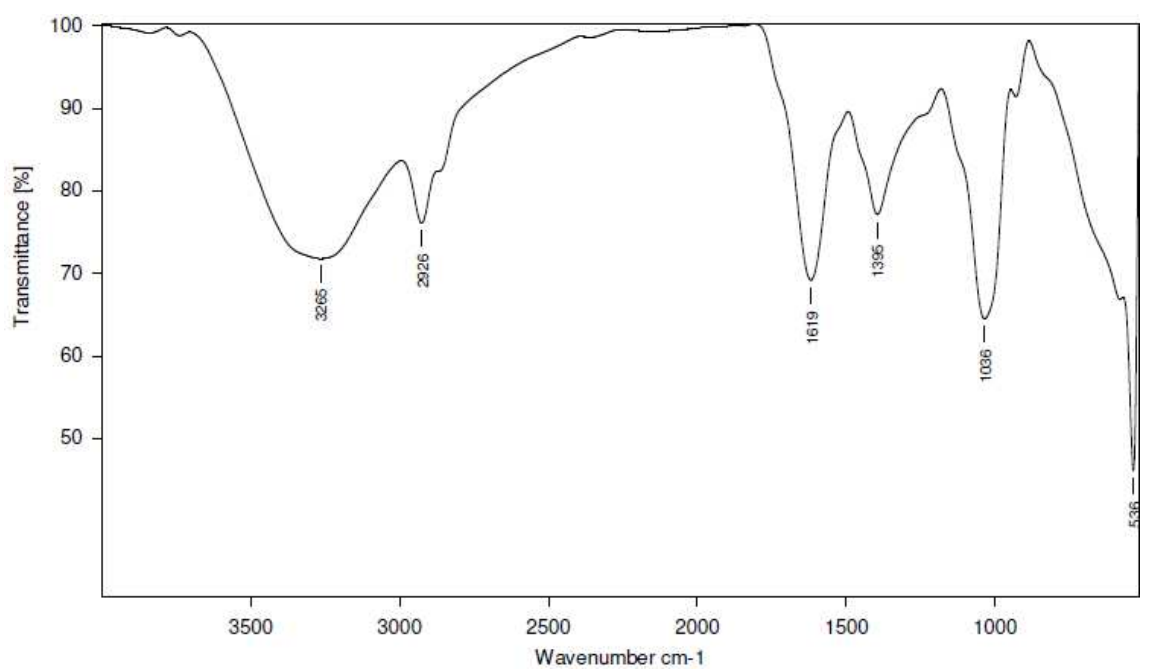

Fig. 1: FTIR spectra of garlic methanolic extract

\section{CONCLUSION}

Our study has revealed the presence of phytochemicals considered as active medicinal chemical constituents in garlic extracts indicated the presence of phenolics, alkaloids, flavonoids, steroids, glycosides, and saponins etc. In summary, methanol was found to be the best solvent for phytochemical screening from garlic cloves, it has showed the best activity among all solvents like hexane, ethyl acetate and water extracts. The values of different metals present in the garlic cloves methanolic extract, the order of concentration of elements is $\mathrm{K}>\mathrm{P}>\mathrm{Mg}>\mathrm{Ca}>\mathrm{Zn}>\mathrm{Al}$. This FTIR revealed the presence of specific functional groups in garlic methanolic extract and showed Hydroxyl, carbonyl, carboxylic and organo-sulfur compounds. Thus we hope that the important properties identified by our study in the garlic will be helpful for the treatment of different diseases.

\section{ACKNOWLEDGEMENT}

Authors are thankful to UGC-OTG, New Delhi, DST-PURSE, SVU and department of chemistry, Sri Venkateswara University for providing necessary facilities like ICPOES and FTIR.

\section{CONFLICT OF INTERESTS}

Declare none

\section{REFERENCES}

1. Ncube NS, Afolayan AJ, Okoh AI. Assessment techniques of antimicrobial properties of natural compounds of plant origin: current methods and future trends. Afr J Biotechnol 2008;7:1797-806.

2. Doss A. Preliminary phytochemical screening of some Indian medicinal plants. Anc Sci Life 2009;29:12-6.

3. Nostro A, Germanò MP, D'angelo V, Marino A, Cannatelli MA. Extraction methods and bioautography for evaluation of medicinal plant antimicrobial activity. Lett Appl Microbiol 2000;30:379-84.

4. Ngari EW, Chiuri LW, Kariuki ST, Huckett S. Ethnomedicine of ogiek of river njoro watershed. Ethnobot Res Applications 2010;8:135-52.

5. Lewis W, Elvin-Lewis M. Medical Botany: Plants Affecting Human Health. $2^{\text {nd }}$ Edn. Wiley and sons, New York; 2003.

6. Joshua Adamu Tende, Joseph Olusegun Ayo, Aliyu Mohammed, Abdulkadir Umar Zezi. Effect of garlic (Allium sativum) and ginger (Zingiber officinale) extracts on haemato-biochemical parameters and liver enzyme activities in Wistar rats. Int J Nutr Food Sci 2014;3:380-6.

7. Wichtl M. Herbal drugs and phytopharmaceuticals, A hand book for practice on a scientific basis. 3rd Edn. Boca Raton, FL: CRC Press; 2004.

8. Williamson E. Potter's Herbal Cyclopaedia. Saffron Walden, Essex: London: CW Daniel Co; 2003.

9. Gruenwald J. The medical economics team PDR physicans desk reference team. Eds. PDR for Herbal Medicines. $3^{\text {rd }}$ Edn. Montvale, NJ: Thomson PDR; 2004.

10. Trease GE, Evans WC. Textbook of pharmacognosy. $12^{\text {th }}$ Edition. Bailliere Tindall, London; 1983. p. 21-2.

11. Harbourne JB. Phytochemical methods: A guide to modern techniques of plant analysis. Third Edition. Chapman and Hall, New York; 1998.

12. Marin Senila, Andreja Drolc, Albin Pintar, Lacrimioara Senila, Erika Levei. Validation and measurement uncertainty evaluation of the ICP-OES method for the multi-elemental determination of essential and nonessential elements from medicinal plants and their aqueous extracts. J Anal Sci Technol 2014;5:1-9.

13. Mikail HG. Phytochemical screening, elemental analysis and acute toxicity of aqueous extract of Allium sativum L. bulbs in experimental rabbits. J Med Plants Res 2010;4:322-6. 
14. Baysal A. Fundamentals of nutrition, Hatipoğlu Press: Ankara in Turkish; 2002.

15. Bartowska J, Litwinczuk Z, Krol J, Kedzierska-Matysek M. Fatty acid profile and minerals content in milk from cows of various breeds over spring-summer feeding period. Pol J Food Nutr Sci 2006;15:13-6.

16. Cashman KD. Milk minerals (including trace elements) and bone health. Int Dairy J 2006;16:1389-98.

17. Zamberlin S, Antunac N, Havranek J, Samarzija D. Mineral elements in milk and dairy products. Mljekarstvo 2012;62:111-25.

18. Aparna Saraf, Aruna Samant. Evaluation of some minerals and trace elements in Achyranthes aspera Linn. Int J Pharma Sci 2013;3:229-33.

19. Haug A, Hostmark AT, Harstad OM. Bovine milk in the human nutrition-a review. Lipids Health Dis 2007;6:25.

20. Soyeurt H, Bruwier D, Romnee JM, Gengler N, Bertozzi C, Veselko D, et al. Potential estimation of major mineral contents in cow milk using mid-infrared spectrometry. J Dairy Sci 2009; 92:2444-54.

21. Rastogi L, Arunachalam J. Sunlight based irradiation strategy for the rapid green synthesis of highly stable silver nanoparticles using aqueous garlic (Allium sativum) extract and their antibacterial potential. Materials Chem Physics 2011;129:558-63.

22. Songsungkan J, Chanthai S. Determination of synergic antioxidant activity of the methanol/ethanol extract of allicin in the presence of total phenolics obtained from the garlic capsule compared with fresh and baked garlic clove. Int Food Res J 2014;21:2377-85.

\section{How to cite this article}

- $\quad$ BJ Divya, B Suman, M Venkataswamy, K Thyagaraju. A study on phytochemicals, functional groups and mineral composition of Allium sativum (garlic) cloves. Int J Curr Pharm Res 2017;9(3):42-45. 